\title{
The Research on the Service Platform System of Cross-border Electronic Commerce
}

\author{
Yuqing WANG \\ Accounting Institute \\ Harbin University of commerce \\ Harbin, China \\ e-mail: 1536941605@qq.com
}

\author{
Xiaojun LU \\ Management Experiment Center \\ Harbin University of commerce \\ Harbin, China \\ e-mail: 1xjharbin@126.com
}

\begin{abstract}
With the deepening of the global economic integration brought by the global network, economic exchanges between countries are becoming more frequent and important. As the technical basis of promoting economic integration and globalization of trade, the cross-border electronic commerce has been well applied and developed in the world, and has a very important strategic significance. According to the Ministry of Commerce data show that in recent years, Chinese rapid growth in cross-border electronic commerce development is a new growth point in the import and export trades. With the development of economy, great progress has been made in cross-border electronic commerce in China. And our country is in the "The Belt and Road" period, which is the important strategic opportunity period. Cross-border electronic commerce industry should seize this rare opportunity, and grasp the state policy. It will become larger, and then turn into the important strategic industry in various regions. But the scale of cross-border electronic commerce development has been limited due to a number of reasons. One of the biggest and most difficult problems is the logistics, information flow and capital flow cannot be unified in a timely manner. The establishment of the service platform system of cross-border electronic commerce, which is based on the Internet of things, cloud computing, big data and some other modern information technologies, is the key to solve this difficult problem. As the key to maintain the rapid growth of cross-border electronic commerce, the service platform system has three aspects of the service platform system. These three different platforms which are built at different levels control the different aspects and assume different functions in the process of foreign trade transactions. These three platforms are closely connected with each other.
\end{abstract}

Keywords-cross-border electronic commerce; service platform; service platform system

\section{IMPORTANCE OF SERVICE Platform SyStem}

Last two years, with the development of economy, great progress has been made in cross-border electronic commerce in China [1]. Nowadays, our country is in the "The Belt and Road" period, which is the important strategic opportunity period. Cross-border electronic commerce industry should seize this rare opportunity, and grasp the state policy. It will become larger, and then turn into the important strategic industry in various regions.
For the moment, the cross-border electronic commerce is in a rapid period of expansion [2]. But the scale of crossborder electronic commerce development has been limited due to a number of reasons. One of the biggest and most difficult problems is the logistics, information flow and capital flow cannot be unified in a timely manner. The establishment of the service platform system of cross-border electronic commerce, which is based on the Internet of things, cloud computing [3], big data [4] and some other modern information technologies, is the key to solve this difficult problem.

As the key to maintain the rapid growth of cross-border e-commerce, the service platform system can provide the basic service platform of cross-border electronic commerce trades for enterprises which is in the areas of Industry Cluster. The platform system is not only to create a perfect crossborder trade's high-speed channel, but also to provide the most practical solution for transformation and upgrading of local foreign trade enterprises [5]. Therefore, it is an urgent that we should build the service platform system of crossborder electronic commerce. The following contents are mainly introduced from three aspects of the service platform system.

\section{THE Clearance SeRvice Platform of CROSS- BORDER E-COMMERCE}

The clearance service platform of cross-border electronic commerce, as the name suggests is a platform system which provides convenient services of import and export for foreign trade enterprises. Due to the development of cross-border trades have become more fragmented [6], traditional customs supervision policy is not convenient for small-sized and medium-sized foreign trade enterprises. Therefore, the General Administration of Customs builds a unified national version of the customs clearance service platform which makes customs clearance process consistent. The data uploaded by the clearance service platform can be directly connected to the internal system of the General Administration of customs, in order to save customs clearance time and improve customs clearance efficiency [7]. On the clearance service platform, the goods through "issuing three lists" (customs declaration of electronic commerce enterprises, payment lists provided by payment enterprises [8], logistics waybills offered by logistics enterprises [9]), checking and issuing lists, collecting and 
reporting lists and counting data method to achieve convenient customs clearance, customs supervision and foreign trade counting of cross-border electronic commerce goods. Customs confirmed that the three lists data is infallible can be allowed to pass. It will be able to achieve online tracking and supervising of goods and make the customs clearance sunnier. Finally, the clearance time is greatly shortened [10].

At present, the clearance service platform mainly service for the parcels of individual buyers and small-scale enterprises. However, the future of the platform should service for a large number of cross-border fragmented orders. The development of cross-border trade enterprises is stable. So are small-scale companies. Small orders are easier to monitor than small parcels. The clearance service platform is also one of the measures of the General Administration of Customs in response to the current fragmentation of foreign trade orders, small parcels, small orders increased dramatically. The clearance service platform matches of enterprise data and customs data, so as to achieve the purpose of monitoring statistics. It provides them with more efficient and convenient logistics customs clearance services, and promotes the sound and rapid development of crossborder electronic commerce.

\section{THE PUblic SeRVICE PlatForm OF CROSS-BORdeR E-COMMERCE}

Since December 2014, the General Administration of Customs issued No.89 documents, set off a national crossborder electronic commerce boom. Once the import and export of goods involved in many sectors, which relates to the State Inspection Bureau, the National Tax Bureau, State Administration of Foreign Exchange, and some other government departments. Cross-border trade enterprises need to negotiate with these departments one by one. It is easy to cause the data mismatch among the various government departments. In particular, the increasing of cross-border electronic commerce scattered parcels and small-sized orders aggravate this phenomenon. On the other hand, cross-border electronic commerce industry has the particularity of order fragmentation. If each order is repeated negotiate with the various functional departments of the government, whether it is for the enterprise or the government, it will undoubtedly become an extremely heavy work. Therefore, the local government needs a supervision statistics platform to ensure the data unified. Thus, cross-border electronic commerce platform for public service become the basic means to solve these problems.

The public service platforms of cross-border electronic commerce are generally invested by local governments to build. There is no national uniform version. And there are differences in the service contents and operating interface among the local platforms. However, these local public service platforms are used "issuing three lists" approach to regulation. With the formalities of "three lists" complete and recognized the enterprises can qualify the normal tax rebate settlement. As a platform for building at the government level, it mainly works in three ways. First, it sets up the public information platform for different local government departments. In addition, the platforms can also directly docking with the customs clearance service platform. The last one is to provide services for foreign trade enterprises. The public service platform is not only building a circle intersection among the various government departments, but also building a bridge for exchanging information between the government and the customs. It is the government opens an important service window for foreign trade enterprises.

\section{THE INTEGRATED SERVICE PlatForm OF CROSS- BORDER E-COMMERCE}

With the continuous improvement of Chinese crossborder electronic commerce regulatory policies, the customs and the local governments gradually tighten gaps of management [11]. However, some of the traditional smallsized and medium-sized foreign trade enterprises and individual sellers are not familiar with the cross-border flow path. When face the supervision of cross-border electronic commerce a period, they are at a loss. In contrast, some large cross-border electronic commerce companies in dealing with cross-border electronic commerce processes are more experienced. Therefore, the integrated service platform of cross-border electronic commerce had been produced. It provides integrated services for small-sized and mediumsized foreign trade enterprises and individual sellers.

Generally, the integrated service platform of cross-border electronic commerce is invested by large cross-border electronic commerce enterprises. Its comprehensive services include finance, logistics, and foreign exchange and so on. The platform is suitable for small parcels, small orders and some other business forms. It has great potential for development. As a platform for building at the enterprises level, it mainly purposes is to provide a one-stop service for small-sized and medium-sized foreign trade enterprises and individual sellers. It is truly service platform for the grassroots. They are platforms for providing comprehensive services, but there are differences among platforms which are built by different enterprises. The best choice for small and medium-sized enterprises is to select the platform which is built by large cross-border electronic commerce enterprise. This large enterprise should have very good credit and ability. The functions of these platforms are relatively complete and the ability to solve problems is also stronger. The most important thing is that the service is secure enough to avoid unnecessary risks and troublesome. There is no doubt that the most credible and secure platform is built by the government.

To sum up, cross-border electronic commerce service platform system should be composed of the clearance service platform of cross-border electronic commerce, the public service platform of cross-border electronic commerce and the integrated service platform of cross-border electronic commerce together. These three different platforms which are built at different levels control the different aspects and assume different functions in the process of foreign trade transactions. These three platforms are closely connected with each other. The information flow, logistics and capital flow are carried on customs declaration of electronic commerce enterprises, logistics waybills offered by logistics 
enterprises, payment lists provided by payment enterprises. With the list, their information is unified exchange and transfer [12]. (As shown in Fig. 1)

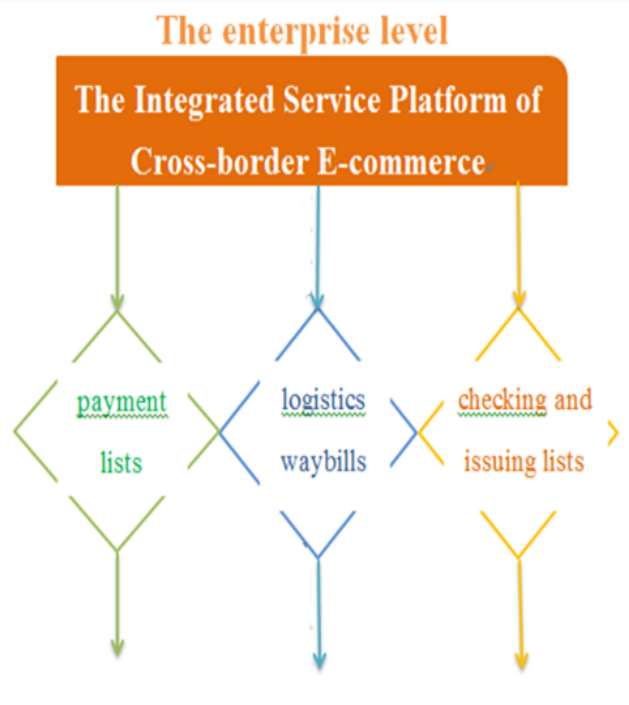

The government level

The Public Service Platform of

Cross-border E-commerce

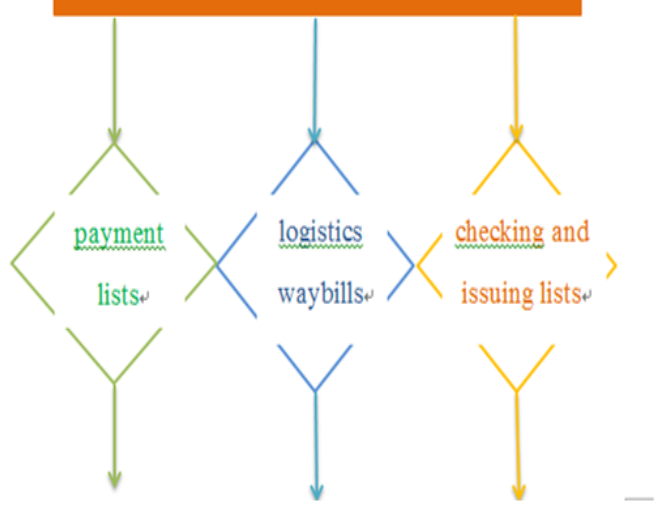

The customs level

The Clearance Service Platform

of Cross-border E-commerce

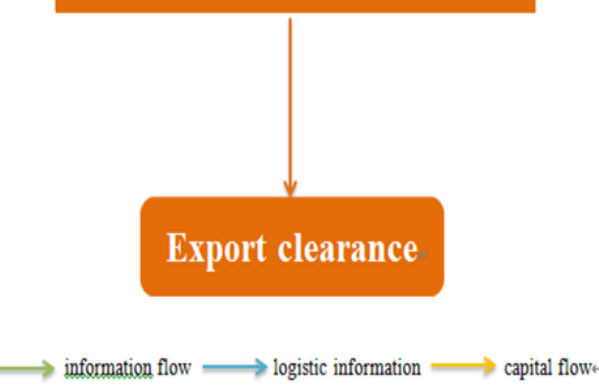

Figure 1. The Workflow of the service platform system of cross-border electronic commerce.

\section{CONCLUSION}

Based on the analysis of the current situation of the development of cross-border electronic commerce, this paper puts forward some suggestions to solve the key problems in the development of cross-border electronic commerce, and draws the following conclusions.

Firstly, the development of cross-border electronic commerce still has a large room for growth. Now, China is very developed both on the side of politics and economy. It has laid a solid foundation for the development of crossborder electronic commerce in China. Secondly, the government should strengthen the policy and market norms to ensure the surrounding of cross-border electronic commerce is safe. At the same time, the domestic crossborder electronic commerce enterprises should also continue to improve their competitiveness. It will push on the development of Chinese cross-border trade. Last but not least, building a complete system of service platform is the only way to achieve the optimal allocation and integration of resources in a wider range. With the promotion and implementation of Chinese "The Belt and Road", the provincial governments and municipal governments, which are in the areas of Industry Cluster, are stepping up efforts to introduce cross-border electronic commerce enterprises settled. And they have issued relevant policies to support such enterprises. However, completing the construction of cross-border electronic commerce service platform system is the most important thing, whether providing services for enterprises or promoting the development of cross-border trade. In practical application, we must make the service platform system perfect and improve the quality of the service platform system. Making the service platform system of cross-border electronic commerce become more diverse and specialized is in order to promote the development of cross-border electronic commerce industry.

\section{REFERENCES}

[1] Iresearch, "The Industry Research Report about cross-border electronic commerce of China in 2015," 2015, pp. 7-9.

[2] E Libin and Huang Yongwen, "A new approach to international trade: a new study of cross-border electronic commerce," Journal of Dongbei University of Finance and Economics, vol. 2, 2014, pp. 1215 .

[3] Zhao Yang and Song Qian, "Research on construction and operation mechanism of electronic commerce service platform in cloud computing environment," Information Technology, vol. 2, Dec. 2014, pp. 21-30.

[4] Wang Zhijun, "Construction scheme of electronic commerce platform," unpublished.

[5] Fang Hong, "Research on foreign trade transformation and upgrading mode and path based on cross-border electronic commerce," The Technology of Telecommunication Network, vol. 5, May 2014, pp.16-18.

[6] Shi Lei, "Discussion on the transformation of foreign trade mode which is under the environment of development of cross-border electronic commerce," Electronic Commerce, vol. 324, Dec. 2016, pp. 27-30.

[7] Wang Ping, "Research on the application of cloud service model in electronic commerce," Modern Business, vol. 33, Apr. 2012, pp. 1920. 
[8] Chen Weidong and Zhu Jianming, "The analysis and countermeasures of payment risk in cross-border electronic commerce," Modernization of Management, vol. 2, Apr. 2016, pp. 35-37.

[9] Zhang Yiming and Zhou Zhigang, "Discussion on cross-border electronic commerce logistics," unpublished.

[10] The Electronic Commerce Research Center of China, "The current situation and suggestions about the development of the cross-border electronic commerce between China and Russian in Heilongjiang," Jan. 2016.

[11] Iresearch, "The Industry Research Report about cross-border import retail electronic commerce of China in 2016," 2016, pp. 5-6.

[12] Hao Yanwei, "Cross-border electronic commerce bonded logistics business model exploration," The Technology of Logistics, vol. 46, Dec. 2016, pp. 48-52. 